\title{
Países em desenvolvimento em uma ordem internacional em transformação: coalizões e soluções de disputas na OMC
}

Developing countries in a changing international order: coalitions and dispute settlement at the WTO

HAROLDO RAMANZINI JUNIOR*

MANUELA TRINDADE VIANA**

Rev. Bras. Polít. Int. 55 (2): 48-69 [2012]

Introdução

No desfecho da primeira e início da segunda década do século 21, as instituições internacionais enfrentam desafios importantes decorrentes das transformações globais e da retomada de discussões sobre parâmetros de legitimidade e de eficiência internacional. Há movimentos buscando o fortalecimento do multilateralismo, para que outros atores participem efetivamente da gestão do sistema internacional, e não apenas os principais países desenvolvidos (PDs), como ocorreu na maior parte do período pós-1945. Observa-se a crise da estrutura existente desde o final da II Guerra Mundial, mais do que propriamente o surgimento de uma nova ordem. Os países em desenvolvimento (PEDs), sobretudo os chamados países emergentes, têm buscado aumentar sua participação nos órgãos internacionais com vistas a alterar as instituiçôes que consolidaram hierarquias no sistema internacional.

De acordo com o ex-ministro das Relações Exteriores do Brasil, Celso Amorim (2010), uma "maior coordenação Sul-Sul - na OMC [Organização Mundial do Comércio], no Fundo Monetário Internacional, nas Nações Unidas e novas coalizões como o BRIC [Brasil, Rússia, Índia e China] - fez aumentar a voz desses países, antes relegados a uma posição secundária”. Esforços de cooperação e de construção de confiança entre alguns países do Sul servem de base para padrões de interação que visam a contornar determinadas pressões dos países desenvolvidos, além de projetar novas modalidades de cooperação internacional, tanto em termos

\footnotetext{
* Professor do Instituto de Economia da Universidade Federal de Uberlândia (UFU), Pesquisador do Centro de Estudos de Cultura Contemporânea (CEDEC) e do Instituto Nacional de Ciência e Tecnologia para Estudos sobre os Estados Unidos (INCT-INEU) (hramanzinijunior@gmail.com).

** Doutoranda em Relações Internacionais pela Pontifícia Universidade Católica do Rio de Janeiro (PUC-Rio) e membro do Núcleo de Pesquisa sobre Desenvolvimento, Comércio, Finanças e Investimento do Centro de Estudos e Pesquisas dos BRICS (m.trindadeviana@gmail.com).
} 
de cooperação técnica e ajuda ao desenvolvimento quanto em termos de formas de cooperação nas principais instituições internacionais. Ao mesmo tempo, a questão torna-se complexa quando se observa que um dos traços característicos dos países do Sul é a sua estratificação: ao mesmo tempo em que alguns países vivenciam níveis elevados de crescimento econômico e de industrialização, outros ainda enfrentam um quadro de pobreza extrema e de instabilidade política. Mesmo os fluxos de comércio entre esses países muitas vezes apresentam significativas assimetrias. Contudo, a noção de "Sul" parece funcionar para os PEDs como um símbolo de mobilização e expressão ideológica do leque de desafios comuns relacionados ao desenvolvimento (Alden e Vieira 2005). Ou seja, trata-se de uma categoria com certa capacidade de amálgama sem que implique necessariamente uma unidade absoluta.

Nas negociações multilaterais de comércio, os PEDs consolidaram a estratégia de articular coalizões com vistas a aumentar seu poder de barganha, mas agora operam em um contexto de mudanças importantes no cenário internacional. Como observa Narlikar $(2003,6)$, "nenhuma coalizão funciona no vácuo, e condições externas favoráveis podem se mostrar cruciais ao contribuir para seu sucesso." Nesse sentido, partimos da ideia de que a reestruturação do poder mundial nos anos 2000 (Kupchan 2002; Buzan 2004; Ikenberry 2008), tendo como fator dinâmico países tradicionalmente não centrais - tal como demonstrado pela ascensão da Índia, da África do Sul, do Brasil e sobretudo da China - tem contribuído para modificações na estrutura de governança do sistema do Acordo Geral sobre Tarifas Aduaneiras e Comércio - General Agreement on Tariffs and Trade (GATT)/OMC. $\mathrm{O}$ regime multilateral de comércio parece estar evoluindo de uma lógica pautada exclusivamente nos interesses das principais potências para uma nova dinâmica onde os PEDs buscam modificar elementos da estrutura e do funcionamento do regime (Steinberg 2002; Hurrell e Narlikar 2006). Essa é uma das razões pelas quais as negociaçôes da Rodada Doha enfrentam dificuldades em avançar: alguns dos interesses de PEDs - especialmente em temas agrícolas - dependem de mudanças nas políticas domésticas ou regionais dos PDs. Contudo, a capacidade de o sistema multilateral de comércio alterar políticas domésticas ou avançar na criação de regras em temas sensíveis aos PDs tem se mostrado limitada (Paalberg 1997), fazendo com que a paralisação das negociaçôes se torne elemento constitutivo da Rodada Doha. Isso não seria uma novidade, já que em rodadas anteriores, como, por exemplo, na Rodada Tóquio ou na Rodada Uruguai, houve também momentos de dificuldade e rompimento das negociações (Tussie e Glover 1995; Deese 2008). A questão é que na Rodada Doha as dificuldades para a evolução das negociações relacionam-se com alguns elementos distintos como o novo ou maior ativismo dos PEDs, estruturado no aperfeiçoamento das suas estratégias de negociação e fortalecido por transformações no âmbito do sistema internacional.

Nesse contexto, o objetivo deste artigo é analisar a atuação dos países em desenvolvimento na $\mathrm{OMC}$, bem como os principais impactos dessa atuação 
na dinâmica da Organização. A análise será articulada segundo dois aspectos: as coalizōes envolvendo $\mathrm{PEDs}^{1}$ e a participação de PEDs no Órgão de Solução de Controvérsias (OSC). Com efeito, as coalizóes e o recurso a mecanismos institucionais são as principais estratégias por meio das quais alguns países do Sul buscam aumentar sua capacidade relativa e emergem como atores importantes na OMC.

$\mathrm{Na}$ próxima seção, discutiremos as principais abordagens teóricas a respeito das coalizões, considerando as motivaçôes que levam os PEDs a se engajarem nesses arranjos de cooperação. Na terceira seção, trataremos das coalizões de PEDs na Rodada Doha, com ênfase no papel do G- $20^{2}$ agrícola no processo de negociação. Essa coalizão constitui uma iniciativa inovadora na cooperação Sul-Sul que redefiniu a estrutura de poder dentro da OMC. Na quarta seção, analisaremos a participação dos PEDs no OSC. Nosso argumento é que a participação de PEDs no OSC tem sido buscada tanto como forma de questionar algumas das políticas de PDs contrárias aos seus interesses quanto como um instrumento de fortalecimento das posições adotadas nas negociaçōes comerciais.

\section{Motivações das coalizões de PEDs}

As coalizões são "formadas por países que, embora apresentem preferências heterogêneas, possuem um conjunto de interesses comuns e adotam uma posição comum nas negociações com o objetivo de aumentar seu poder coletivo de barganha" (Constantini et al. 2007, 866). Na OMC, os PEDs possuem, individualmente, poder reduzido de influência nas negociações envolvendo grandes potências. Alguns PEDs carecem de conhecimentos técnicos exigidos na dinâmica de negociações; outros dispóem de recursos limitados para arcar com custos de viagens e delegações permanentes em Genebra. Ademais, a ação via coalizões pode resultar em uma divisão de pesquisa e trabalho nos diversos temas negociados, ou pode reduzir os custos políticos de bloqueio de um acordo, ao dissipar a responsabilidade entre os membros.

Ao barganharem juntos, os PEDs representam uma parcela maior do comércio mundial e, por esse motivo, podem exercer maior influência, além do aumento da

1 A OMC classifica seus membros de acordo com duas categorias: países desenvolvidos e países em desenvolvimento. Os países em desenvolvimento são uma categoria composta por países em desenvolvimento e países de menor desenvolvimento relativo - Least Developed Countries (LDCs). Esse procedimento visa a diferenciar a implementação dos acordos do sistema GATT/OMC de acordo com as capacidades relativas dos países membros. A condição de país em desenvolvimento possibilita um maior período de transição antes da implementação de um acordo e também uma assistência técnica da organização. Contudo, não há um critério formal para cada uma dessas categorias: os países se autointitulam desenvolvidos ou em desenvolvimento. É possível que os membros desafiem a decisão de um país de fazer uso de provisōes disponíveis para países em desenvolvimento. Por exemplo, durante os anos de 2003 e 2004, houve um movimento dos Estados Unidos e da União Europeia com vistas a graduar o Brasil e mudar o status de país em desenvolvimento utilizado pelo país na organização.

2 São membros do G-20: África do Sul, Argentina, Bolívia, Brasil, Chile, China, Cuba, Egito, Filipinas, Guatemala, Índia, Indonésia, México, Nigéria, Paquistão, Paraguai, Tailândia, Tanzânia, Uruguai, Venezuela e Zimbábue. 
densidade política possibilitada pela ação conjunta. Nesse sentido, as propostas apresentadas por um número significativo de membros tendem a ser recebidas como mais legítimas. A ação mediante coalizões amplia, ainda, as possibilidades de participação ou de representação efetiva nas reuniões da green room. ${ }^{3}$ As coalizões permitem que alguns países apresentem propostas conjuntas em situações nas quais provavelmente não o fariam se tivessem que fazê-lo isoladamente. Grande parte da literatura converge quanto ao argumento de que os PEDs, de modo geral, devem formar coalizões para reforçar seus interesses nas negociaçōes (Narlikar 2003; Odell 2003; Constantini et al. 2007; Patel 2007).

Por outro lado, o principal custo de participação em coalizões pode relacionarse à necessidade de concessões excessivas dentro do grupo com vistas à coordenação de posições (Fernández 2008). Geralmente, os custos da ação em grupo aumentam conforme a diversidade de preferências dos membros nas negociações. A barganha conjunta é profícua quando são previamente consideradas questôes como com quem, contra quem, com que pauta e por quanto tempo a coalizão atuará (Narlikar 2003).

Narlikar $(2003,31)$ formulou uma tipologia das coalizões nas negociações do sistema GATT/OMC: aliança e bloco. Coalizões de tipo aliança são baseadas em temas específicos e perduram enquanto a causa original de sua emergência persiste. Já as coalizões de tipo bloco revelam grande durabilidade, na medida em que se adaptam a novos temas, mesmo após o eventual equacionamento do tema que motivou o seu surgimento. Nesse segundo tipo de coalizão, a ação conjunta pode estar fundamentada em semelhanças e afinidades preexistentes com outros Estados muitas vezes oriundas de dinâmicas que não se restringem ao regime de comércio. Grande parte das coalizões envolve elementos de ambos os tipos, como no caso do G-20 agrícola, conforme será discutido na próxima seção. No entanto, a tipologia oferecida por Narlikar (2003) é de utilidade analítica, pois pode ajudar a entender como diferentes formas de articulação de coalizões podem produzir resultados distintos.

Tanto a coalizão de aliança como a de bloco, entretanto, pode enfrentar problemas de ação coletiva, incoerência interna e falta de influência efetiva. De acordo com Olson (1999), as coalizóes enfrentam problemas de ação coletiva porque, quanto maior o grupo, menor a relevância das contribuições individuais, o que resulta em casos de free-riding. Ao lidar com esse fator, Hardin (1982) argumenta que o dilema da ação coletiva em grupos grandes pode ser superado mediante a ação de "empreendedores políticos", que estejam dispostos a assumir os custos da ação coletiva de forma desproporcional, desde que seus interesses - tais como projeção e liderança - sejam alcançados. No contexto da OMC, a literatura considera que

3 De acordo com Srivastava $(2008,38)$ as reuniōes da green room são "informal meetings limited to representative nations of the various groups having leverage in international negotiations [...]. Deals negotiated in the Green Room have usually been accepted and become part of the final declaration with trivial amendments." 
o papel de empreendedor político de coalizões é normalmente desempenhado por países intermediários, como, por exemplo, economias emergentes e/ou líderes regionais. As chances de sucesso de uma coalizão de PEDs são maiores se duas condiçōes forem satisfeitas: a) coerência interna; e b) peso ou influência externa (Narlikar 2003) - ambas as características apresentadas pelo G-20. Nessa coalizão, Brasil e Índia desempenharam o papel de empreendedor político.

\section{Coalizões de PEDs na Rodada Doha}

Durante as negociações do GATT, os PEDs revelavam uma participação limitada nas negociações devido às estratégias de desenvolvimento orientadas para o contexto doméstico. Nesse período, suas estratégias não eram compatíveis com os principais objetivos do regime de comércio quanto à redução de barreiras tarifárias e não tarifárias. Os PEDs que tinham alguma atuação concentravam-se, principalmente, na demanda de tratamento especial e diferenciado. As negociações do GATT eram consideradas, em grande medida, um "clube de ricos", no qual apenas os mais poderosos eram capazes de avançar seus interesses (Narlikar 2003); os PEDs tinham algum ganho indireto com as negociaçôes de diminuição tarifária entre os ricos, por conta do princípio da nação mais favorecida.

Embora a mudança tenha começado antes - provavelmente na Rodada Tóquio -, foi durante a Rodada Uruguai (1986-1994) que a transformação no posicionamento dos PEDs em relação ao GATT se tornou mais proeminente. A referida Rodada incorporou novos itens à agenda, em um esforço dos PDs liderados pelos EUA - de adequar as políticas domésticas dos países membros a padrões liberais (Velasco e Cruz 2007). Além de inibir a adoção de medidas restritivas ao comércio internacional, a Rodada também visava à regulação de políticas nacionais (Ostry 2002). Os PEDs reagiram entrando definitivamente no sistema, com vistas a tentar reduzir a interferência do GATT na dinâmica doméstica e bloquear a incorporação de novos temas à agenda, em especial serviços e propriedade intelectual. Contudo, esse posicionamento não pôde ser mantido em decorrência de dificuldades domésticas, da pressão dos PDs e da distribuição internacional de poder. A partir de 1988, com o Mid-term Review, os PDs - principalmente EUA e Comunidade Europeia - conduziram a agenda e controlaram grande parte do processo de negociaçōes até a fase final da Rodada Uruguai (Tussie e Glover 1995; Farias 2009). Portanto, a trajetória inicial do sistema GATT/OMC sugere que os interesses dos PEDs foram amplamente marginalizados, o que resultou em textos que refletiam os interesses dos poderes políticos e econômicos dominantes (Wilkinson 2006).

Em contraste, o mandato voltado ao desenvolvimento da atual Rodada Doha (2001-presente) sinaliza o papel crescente dos PEDs na OMC, ainda que a presença de um tema ou questão no mandato negociador não necessariamente 
garanta a sua negociação efetiva (Steinberg 2002; Narlikar e Tussie 2004)4. A atenção do Mandato de Doha às economias menores (parágrafos 35 e 36) e aos países de menor desenvolvimento relativo (PMDRs) (parágrafos 42, 43 e referências diversas) pode ser explicada pelos esforços do Grupo das Economias Pequenas e Vulneráveis e pelas coalizões formadas por PMDRs, respectivamente. Da mesma forma, a decisão de incorporar um waiver ao Acordo de Parceria entre ÁfricaCaribe-Pacífico-Europa - Partnership Agreement between the African, Caribbean and Pacific Group of States and the European Community (ACP-EC) - constituiu resultado dos esforços dos países do ACP e dos Grupos Africanos.

A coalizão Core Group on Singapore Issues surgiu a partir da oposição à negociação dos quatro temas de Cingapura como um único pacote. Devido à pressão dessa coalizão, três dos temas de Cingapura - investimentos, compras governamentais e concorrência - foram removidos da agenda da Rodada Doha no conhecido Pacote de Julho de 2004. Embora o Pacote tenha mantido temas como facilitação do comércio, os PEDs não serão demandados a implementar as decisões no acordo final se carecerem de infraestrutura adequada ou capacidade de implementação. A coalizão Membros Recentemente Ingressos - Recently Acceded Members (RAMs) - buscou garantir um tratamento diferenciado aos membros nessas condições, já que, no processo de adesão à OMC, os níveis de compromisso exigidos desses países foram altos. A coalizão Cotton-4, por sua vez, foi formada para demandar a eliminação completa dos subsídios no setor de algodão, bem como a implementação de um mecanismo de compensação financeira até que os subsídios sejam eliminados. Essa coalizão contribuiu, ainda, para a vitória brasileira contra os EUA no contencioso sobre algodão (DS267) (Baffes 2011).

Ademais, a Declaração de 2001 sobre Aspectos de Direitos de Propriedade Intelectual Relacionados ao Comércio - Trade-Related Aspects of Intellectual Property Rights (TRIPS) - e Saúde Pública reflete, em grande medida, a agenda dos PEDs, muito por conta da atuação da coalizão TRIPS e Saúde Pública (Drahos 2003). Brasil, Índia e África do Sul desempenharam um papel crucial para tornar o Acordo de TRIPS mais flexível e contribuíram para contrapor a pressão dos PDs pelo enforcement das patentes de companhias farmacêuticas dentro de uma interpretação estrita do Acordo de TRIPS. Essas negociações representam um exemplo importante de como as instituições internacionais podem oferecer um espaço político para que os países mais fracos se articulem em coalizões com atores

4 Referindo-se ao lançamento da Rodada Doha, em novembro de 2001, a avaliação de um jornal britânico era que "the most significant story to emerge from the talks in the Gulf is the coming of political age of the developing country lobby within the WTO. Doha marks a turning point. It was not the radical climax for which some campaigners hoped, but it is a significant shift in the balance of power in global trade negotiations away from a small coterie of rich industrialized nations." Developing Countries flex their muscles. Disponível em <http://www.guardian.co.uk/world/2001/nov/15/globalisation.guardianleaders>, acessado 27 nov. 2011.

5 Doha WTO Ministerial 2001: Ministerial Declaration (WT/MIN(01)/DEC/1). Disponível em <http://www.wto.org/english/thewto_e/minist_e/min01_e/mindecl_e.htm>, acessado 27 nov. 2011. 
governamentais e não governamentais para alcançar seus interesses (Odell 2003; Shaffer 2007).

O G-20, que será discutido mais detidamente na próxima seção, também desempenhou um papel central na elaboração do Pacote de Julho de 2004 e na Conferência Ministerial de Hong Kong, em 2005. O Grupo manteve uma posição consistente nas modalidades de negociaçóes ao longo das reuniões de 2006. Apesar do colapso da atuação do G-4 (formado por Brasil, Índia, UE e EUA) na Reunião Ministerial realizada em Potsdam, em 2007, e das dificuldades observadas durante a reunião ministerial de Genebra, em julho de 2008, a força crescente dos PEDs nas negociações multilaterais de comércio é um fato importante que, inclusive, ajuda a entender as próprias dificuldades da negociação na medida em que uma quantidade maior de interesses necessariamente deve ser levada em consideração para que a negociação caminhe.

À luz do acima exposto, parece plausível referir-se à Rodada Doha como a rodada das coalizões - ao menos sob a perspectiva dos PEDs. Isso não significa que as coalizões não atuavam nas rodadas anteriores (ver Tabela 1); no entanto, foi na Rodada Doha que se observou uma proliferação de coalizões envolvendo PEDs, com um grau mais elevado de institucionalização relativa (Hurrell e Narlikar 2006; Ismail 2009).

Tabela 1. Coalizões de PEDs no GATT/OMC (1973-2007).

\begin{tabular}{l|l}
\multicolumn{1}{c|}{ Período } & \multicolumn{1}{c}{ Coalizão } \\
$\begin{array}{l}\text { 1973-1979 } \\
\text { (Rodada Tóquio e pré- } \\
\text { Uruguai, até 1986) }\end{array}$ & $\begin{array}{l}\text { Grupo da ASEAN (1973); Grupo Informal de Países em } \\
\text { Desenvolvimento (1982); Grupo Café au Lait (1983). }\end{array}$ \\
\hline $\begin{array}{l}1986-1994 \\
\text { (Rodada Uruguai) }\end{array}$ & $\begin{array}{l}\text { Países em Desenvolvimento sobre Serviços (1986); Grupo Cairns (1986); } \\
\text { Serviços de Transportes Aéreos (1986); Grupo de Importadores de } \\
\text { Alimentos (1986); Grupo Latino-americano (1986); Mercosul (1991). }\end{array}$ \\
\hline $\begin{array}{l}\text { 1995-2007 } \\
\text { pós-estabelecimento } \\
\text { da OMC) }\end{array}$ & $\begin{array}{l}\text { Pré-Rodada Doha (1995-2001) } \\
\text { Like-Minded Group (LMG) (1996); Economias Pequenas e Vulnerá- } \\
\text { veis - Small and Vulnerable Economies (SVEs) (1996); Grupo Africa- } \\
\text { no (1997); CARICOM (1997); Amigos dos Peixes (1998); Amigos das }\end{array}$ \\
$\begin{array}{l}\text { Indicações Geográficas (1998); Amigos da Caixa de Desenvolvimento } \\
\text { (1999); G-24 sobre Serviços (1999); Grupo de Países de Menor Desen- } \\
\text { volvimento Relativo (1999); Grupo Paradisus (2000). }\end{array}$ \\
$\begin{array}{l}\text { Rodada Doha (2001-2007) } \\
\text { Grupo África, Caribe e Pacífico (ACP) (2001); Grupo Central sobre os } \\
\text { Temas de Cingapura (2001); Membros de Adesão Recente (RAM, sigla } \\
\text { em inglês) (2003); Cotton-4 (2003); Amigos do Antidumping (2003); } \\
\text { G-110 (2005); G-20 (2003); G-33 (2003); G-90 (2003); Grupo } \\
\text { Central sobre Facilitação de Comércio (2005); NAMA-11 (2005) }\end{array}$
\end{tabular}

Fonte: Patel (2007). 
Na Rodada Doha, as coalizões têm se concentrado em atuar no âmbito da estrutura institucional de comércio existente - em vez de desafiar o sistema - e passaram por um processo de formalização, mantendo escritórios junto ao secretariado da organização em Genebra e realizando reuniōes em nível ministerial com o objetivo de formalizar posições. Atualmente, as coalizões desempenham papel mais visível, divulgam declarações, realizam conferências de imprensa e campanhas e interagem com redes de mídia e da sociedade civil.

Como resultado da atividade das coalizóes de PEDs, a OMC "agora incorpora as coalizões no processo formal de tomada de decisão” (Patel 2007, 17-18), permitindo que representantes desses grupos participem de reuniões no green room. Todavia, essa mudança institucional pode constituir apenas uma tentativa da OMC de aprimorar sua legitimidade institucional. Além disso, do ponto de vista dos PEDs, participação não é sinônimo de influência nas negociações. Reconhecer a diferença entre esses dois conceitos e estabelecer critérios para diferenciá-los é um desafio importante para a literatura sobre coalizões de PEDs na OMC.

A proliferação de coalizões Sul-Sul incentivou a cooperação entre esses grupos, os quais em determinados momentos passaram a compartilhar informações entre si, realizar conferências de imprensa conjuntas e reuniōes bilaterais. De acordo com Patel $(2007,10)$, o exemplo mais proeminente disso é a "aliança do G-110, que surgiu nos estágios finais da Ministerial de Hong Kong e que os membros descreveram como um diálogo entre G-20, G-33, Grupo África, Caribe e Pacífico (ACP), Grupo de Países de Menor Desenvolvimento Relativo (PMDRs), Comunidade do Caribe (CARICOM), Cotton-4, Grupo de Economias Pequenas e Vulneráveis (SVEs) e Grupo de Acesso a Mercados para Bens Não Agrícolas (NAMA-11)". Iniciativas mais formais também foram feitas para coordenar as posições entre as coalizões, com destaque para a mobilização do G-90 na Ministerial de Cancún, que envolvia o Grupo Africano, ACP e PMDRs (Patel 2007).

É possível que a cooperação em uma coalizão produza efeitos de radiação, tais como o fortalecimento dos laços entre os países membros e o estímulo a ações conjuntas em outras coalizões e arenas. Nesse sentido, Ismail (2007) sustenta que o G-20 foi importante para a formação da coalizão Non-Agricultural Market Access (NAMA-11) ${ }^{6}$, pouco antes da Conferência Ministerial de Hong Kong, em 2005. De modo similar, Narlikar $(2003,15)$ argumenta que as coalizões muitas vezes apresentam repercussões em outras instituiçôes: a vantagem de pertencer a uma coalizão multilateral pode gerar um efeito de spill over em outros acordos multilaterais e bilaterais. O G-20 é um exemplo de como os PEDs foram capazes de superar suas próprias divergências e estabelecer uma frente comum de negociação durante parte importante da negociação.

6 Os membros da coalizão NAMA-11 apresentam propostas conjuntas nas negociações de Acesso a Mercado para Bens Não Agrícolas (NAMA). De acordo com Ismail (2007) a coalizão foi exitosa no sentido de estabelecer uma ligação entre o nível de ambição das negociaçôes de NAMA e as negociaçốes de agricultura no texto final da Declaração de Hong Kong. 
Dessa forma, a formação de coalizões é um recurso importante para a cooperação e o empoderamento de PEDs na OMC. No entanto, em termos gerais, a coordenaçãao entre os PEDs na Organização ainda apresenta um caráter predominantemente reativo em relação à posição e aos interesses dos países do Norte. Mesmo o caso do G-20 sugere que as posições dos PDs constituem um fator importante na formação de coalizões de PEDs na OMC.

\section{O G-20: um marco na cooperação Sul-Sul}

A criação do G-20 no estágio preparatório da Conferência Ministerial de Cancun (2003) resultou de esforços de PEDs - liderados por Brasil e Índia - para reduzir a capacidade dos PDs de impor suas posiçōes. Diferentemente da Rodada Uruguai, quando o acordo agrícola elaborado pelos EUA e pela UE (Blair House) pavimentou o caminho para a conclusão da rodada, a proposta apresentada em 2003 por EUA e UE enfrentou forte oposição por parte dos PEDs. O surgimento do G-20 representa uma resposta à proposta de negociação agrícola, estruturada e predeterminada pelos Estados Unidos e União Europeia.

De certo modo, a formação do G-20 representou a retomada efetiva do espírito da cooperação Sul-Sul no âmbito da OMC. Após um período de euforia liberal, nos anos 2000, muitos países do mundo em desenvolvimento começaram a reavaliar suas opções de política externa projetando ações fundamentadas na lógica da autonomia e buscando fortalecer a articulação com seus pares; ainda que esse não seja um processo generalizado ou automático. De acordo com Hurrel e Narlikar (2006), a Conferência de Cancún representa uma ruptura com o consenso neoliberal da década de 1990 . O G-20 aponta para uma tendência em direção a posiçôes mais assertivas dos PEDs no sistema internacional, tanto individual quanto coletivamente, e representa um importante ponto de inflexão na trajetória do regime de comércio (Vigevani e Ramanzini Júnior 2010).

A coalizão logrou equilibrar os interesses dos PEDs com fortes setores agrícolas - como Brasil e Argentina (também membros do Grupo Cairns) - com aqueles cuja agricultura é predominantemente familiar - como Índia e China (membros do G-33). Nesse sentido, o G-20 propôs cortes radicais nos subsídios domésticos e à exportação dos PDs, bem como um maior acesso a mercado. Ao mesmo tempo, para atender às demandas dos importadores agrícolas, o Grupo exigiu a aplicação de uma fórmula diferenciada para acesso a mercado e propôs um Tratamento Especial e Diferenciado para PEDs. Os países do G-20 concordaram, entretanto, quanto à eliminação dos subsídios concedidos à exportação de produtos agrícolas nos PEDs (MRE 2007).

Brasil e Índia juntaram-se a EUA, UE e Austrália para formar o grupo das Cinco Partes Interessadas - Five Interested Parties (FIPs) -, os principais atores na configuração do Acordo-Quadro de julho de 2004. O Pacote de Julho foi capaz de avançar as negociações em agricultura: adotou uma abordagem em etapas 
para acesso a mercado, uma "redução substancial do apoio interno" e reforçou o compromisso no estabelecimento de um prazo definitivo para a completa eliminação de todos os subsídios à exportação. Segundo Deese (2008), o G-20 desempenhou um papel significativo nesses resultados por meio da atuação dos ministros do Brasil e da Índia.

O G-20 enfrentou desafios para sua manutenção à afirmação, desde a sua criação, em 2003. Para continuar a negociar acordos bilaterais de livre comércio com os EUA, por exemplo, Peru, Costa Rica e Colômbia foram forçados a abandonar sua filiação ao G-20 (Srivastava 2008). Gradualmente, entretanto, o grupo obteve o reconhecimento internacional por sua posição nas negociações agrícolas, tendo sido importante a proposta sobre acesso a mercado apresentada em 2004, já que esse era um tema sensível entre os membros da coalizão. O G-20 também obteve reconhecimento pelo conteúdo técnico de suas propostas nas várias reuniōes dos grupos de trabalho realizadas em Genebra. O fato de muitas das propostas do G-20 constituírem a base das negociaçóes evidencia o poder do grupo em influenciar a agenda das negociaçóes agrícolas (Ramanzini Júnior 2009).

Mesmo assim, os membros do G-20 passaram por momentos de divergência. $\mathrm{Na}$ reunião de julho de $2008^{7}$, em Genebra, o G-20 foi incapaz de elaborar um documento comum. A principal divergência estava relacionada ao critério a ser adotado para o uso do Mecanismo de Salvaguarda Especial - Special Safeguard Mechanism (SSM). O G-20 aceitou o referido mecanismo em seu pacote geral de propostas como uma concessão de alguns países (como o Brasil) para manter o bloco coeso na fase inicial e intermediária da negociação. Contudo, os membros da coalizão não alcançaram um acordo nessa área na etapa final das negociaçôes: o Brasil aceitou a proposta de acordo da OMC com critérios de SSM consideravelmente abaixo daqueles exigidos pela Índia e pela China, incluindo níveis considerados toleráveis para o acesso ao mercado de produtos industriais do Brasil. Esta última proposta foi fortemente criticada por Índia, China, África do Sul e Argentina. Isso oferece algumas evidências de que os países do Sul não formam um grupo homogêneo e de que os PEDs nem sempre possuem a mesma visão sobre como lidar com os desafios globais, sobretudo em estágios decisivos de negociações.

Desde a sua criação, o G-20 enfrentou vários desafios, comuns inclusive às coalizôes de PEDs: risco de fragmentação, dificuldades de reconhecimento, divergência de interesses entre seus membros e ênfase em uma estratégia distributiva. Apesar dessas vulnerabilidades, a coalizão permaneceu unida durante as negociações, ao menos até a reunião ministerial de julho de 2008. Uma possível explicação para isso, de acordo com Narlikar e Tussie (2004), é que os países do G-20 passaram por um processo de aprendizado com as normas e regras da OMC, também fruto de suas experiências pretéritas de ação coletiva. Teriam agora maior clareza do

7 Para uma análise detalhada da reunião ministerial de julho de 2008, ver Ismail (2009). 
tipo de comportamento e postura que é favorecida pela organização ou que tem maior chance de sucesso e reconhecimento institucional. A coalizão reuniria assim elementos tanto do tipo bloco como das coalizóes baseadas em temas específicos.

A experiência da formação e a da atuação do G-20 na Rodada Doha da OMC traz questôes interessantes para a cooperação Sul-Sul de forma mais geral. Primeiramente, o papel do "empreendedor político" para a manutenção da coalizão - geralmente, um país intermediário - foi uma constante na experiência do G-20. As constantes reuniōes entre os membros levaram ao intercâmbio regular de informações, bem como à construção de confiança interna entre os países da coalizão. Diálogos e iniciativas conjuntas com outras coalizôes e com funcionários da $\mathrm{OMC}$, assim como a apresentação de propostas técnicas e substantivas ${ }^{8}$, contribuíram para um maior reconhecimento da importância do G-20. Ao questionar a centralidade dos países desenvolvidos nas negociações e ao projetarse como ator relevante, cuja posição deveria ser levada em consideração, o G-20 assinalou uma mudança nas relações de poder dentro da Organização. Por fim, os líderes da coalizão, Brasil e Índia, revelaram transparência nas negociações ao apresentarem, para os demais membros da coalizão, relatos frequentes sobre as negociações do green room. Essa conduta não necessariamente deve ser interpretada como um altruísmo, mas como uma ação alinhada com o interesse dos países na manutenção da coalizão durante parte do processo negociador.

Quando os PEDs - tanto no G-20 como em outras coalizóes Sul-Sul - logram controlar os fatores externos que motivaram a formação da coalizão, enfrentam dificuldades em continuar a agir coletivamente. As dificuldades em matéria de coordenação política entre os membros do G-20 na reunião ministerial de julho de 2008, em Genebra, é um bom exemplo dessa situação. Outra explicação pode ser parcialmente identificada nos interesses domésticos dos países, nas diferentes estruturas econômicas, políticas e sociais. Na reunião ministerial de julho de 2008, quando houve uma oportunidade para ação na qual os interesses do Brasil - o principal líder do grupo - estavam relativamente contemplados, as concessões feitas em favor da ação coletiva foram parcialmente abandonadas. Em referência à reunião e à posição brasileira, o ex-presidente Lula da Silva declarou que "não houve divergência de conceitos" com a Argentina e outros PEDs. Mas ele reconheceu que, geralmente, em momentos críticos, o interesse nacional prevalece em decisōes governamentais: "não devemos ver, em nossas diferenças, situações de conflito, mas situações de diferença; diferenças econômicas e diferenças de potencial industrial" (Clarín 2008). Esse episódio permite avaliar as possibilidades e os limites de uma cooperação que parcialmente pressupõe visões de mundo e valores com alguma semelhança.

8 De acordo com Tussie (2009, 3), "a negotiator demanding a very high level of concessions from the opponent or refusing to make any concessions will be taken more seriously when backed up by detailed studies [...]. The purpose of research cannot be understood narrowly as self-serving because the most important function is to justify and explain demands of one group to other groups.” 
As afinidades entre os PEDs abrem portas e promovem certos entendimentos, mas é preciso reconhecer o fato de que a política externa e a cooperação internacional estão relacionadas, acima de tudo, com o interesse dos atores (Keohane 1984). Os interesses são inerentes aos Estados e possuem importância central para a formação e manutenção de uma coalizão. Mesmo se alguns desafios comuns constituírem um símbolo de mobilização e unificação, não se pode subestimar as diferenças entre os PEDs que desafiam parte das iniciativas de cooperação.

Na próxima seção, analisaremos a participação dos PEDs no OSC. Veremos que a participação crescente desses países nesse mecanismo, embora concentrada em um pequeno grupo, pode promover tanto os interesses de PEDs especificos quanto dos PEDs de modo mais amplo.

\section{Participando com dentes: os PEDs e as soluções de controvérsias da OMC}

Outra forma com que os PEDs passaram a promover seus interesses no sistema multilateral de comércio relaciona-se com o OSC - um instrumento distintivo da estrutura da OMC. A importância desse mecanismo reside em seus procedimentos e estrutura, voltados a garantir a implementação dos acordos da Organização e dos compromissos específicos assumidos pelos países. No que diz respeito aos PEDs, a importância do OSC pode ser identificado em três aspectos: garantir direitos; evitar a preeminência da hegemonia econômica; e assegurar que os choques sistêmicos não prejudicarão seus interesses (Qureshi 2003, 175). Até o momento, os PEDs não colaboraram de forma direta no âmbito do OSC, ainda que haja evidências de que os países participam como terceira parte em painéis que envolvem seus interesses. Todavia, o uso bem-sucedido do OSC tem a capacidade de influenciar os resultados das negociações de modo mais amplo, como no caso da disputa sobre o algodão entre Brasil e EUA.

Esses benefícios não são homogeneamente distribuídos pelos PEDs. Por exemplo, apenas um PMDR abriu um painel contra outro membro da OMC?. De forma similar, a ausência de países da África subsaariana - muitos dos quais são classificados como PMDRs - em painéis da OMC inspirou muitos analistas a questionar a importância do OSC para os países africanos (Alavi 2007; Mosoti 2003).

A notória disparidade entre PMDRs e outros membros da $\mathrm{OMC}$ quanto à participação em painéis pode ser parcialmente compreendida a partir do princípio do tratamento especial e diferenciado, segundo o qual os PMDRs dispóem de um período de transição mais longo para implementar suas obrigações da OMC. Também, muitas das disputas envolvendo esses países são estabelecidas sob

9 O país demandante do painel em questão foi Bangladesh em 24 de janeiro de 2004 e o país demandado foi a Índia. Ver: DS306 - Antidumping Measure on Batteries from Bangladesh. 
acordos preferenciais de acesso a mercado assinados pelos PMDRs com alguns PDs. A pequena parcela do comércio mundial representada pelos PMDRs - em torno de $0,54 \%$ em 2000 - é recorrentemente evocada como explicação para sua ausência em painéis na OMC. Dados os constrangimentos de recursos que esses países enfrentam, é provável que os PMDRs optem por dedicar mais recursos para outras iniciativas e gestôes de comércio, em vez das disputas no âmbito do OSC. Por outro lado, apesar de não comercializar o volume e a variedade de produtos que os principais membros da OMC, as barreiras comerciais enfrentadas pelos PMDRs podem apresentar uma importância relativa maior para suas economias. Assim, "enquanto eles podem ter menos ganhos absolutos em jogo no sistema de comércio em relação ao total do comércio mundial, podem ter mais ganhos relativos em comparação às suas respectivas economias" (Shaffer 2007, 178-9).

Pelo fato de os PMDRs constituírem um subgrupo da categoria PEDs, alguns dos elementos mencionados acima também são pertinentes aos PEDs de forma geral. Mais precisamente, os PEDs encontram-se em condições de desvantagem comparativamente aos PDs em termos de avaliar os custos e benefícios de determinado painel, bem como de arcar com os custos de um painel ao longo do tempo. Os desafios são basicamente três: uma carência relativa de conhecimentos técnicos quanto às regras da $\mathrm{OMC}^{10}$; recursos financeiros limitados ${ }^{11}$; e margem de manobra política reduzida. Além desses obstáculos, de modo geral, os PEDs enfrentam dificuldades burocráticas internas, tais como a concentração de questões relativas à solução de controvérsias em torno do Ministério das Relações Exteriores, a falta de apoio das capitais e a falta de apoio financeiro e informacional de seu setor privado (Shaffer 2007). Ademais, diferentemente da Representação dos EUA para o Comércio - United States Trade Representative (USTR) - e do Comissário Europeu para o Comércio, muitos PEDs não possuem uma instituição doméstica ou regional especialmente voltada a temas de comércio internacional.

Certamente, essas dificuldades exerceram pressão sobre o desempenho dos PEDs em sua trajetória de soluções de disputas no OSC da OMC. Uma forma interessante de se avaliarem as condiçóes de acesso impostas a todos os membros da OMC é analisar a incidência do status de demandante em determinada categoria ${ }^{12}$, uma vez que isso ilustra que o país ponderou os custos e benefícios da disputa. Esse processo constitui um estágio essencial da rationale por trás do sistema de solução de controvérsias, tendo em vista o amplo reconhecimento de que os painéis são longos, morosos e custosos.

10 Alguns órgãos da OMC e organizações não governamentais têm desenvolvido programas com vistas a oferecer assistência técnica aos países em desenvolvimento, especialmente os LDCs, para que possam acompanhar de forma mais efetiva o andamento das negociações. Para maiores informações sobre esses programas ver: Shaffer (2006).

11 Segundo Shaffer (2006, 190), a solução de controvérsias na OMC é "so expensive that many developing country enterprises simply cease exporting to the United States or Europe upon the initiation of a complaint."

12 Por outro lado, a efetividade do OSC pode ser entendida a partir de uma análise específica das decisões do sistema. 
Isso posto, é possível argumentar que a participação dos PEDs como demandantes em painéis de solução de disputas foi mais fortemente limitada nos cinco primeiros anos após a criação do OSC. De 1995 a 2000, os PDs estiveram envolvidos como reclamantes em 157 painéis, em contraste com os 79 painéis abertos por PEDs (ver Gráfico 1). Esse cenário contrasta com os dados observados nos anos seguintes, quando os PEDs passaram a participar mais ativamente de soluçōes de disputas que os PDs. De 2001 a 2006, os PEDs foram partes reclamantes em 81 ocasiōes, enquanto os PDs, 57 vezes.

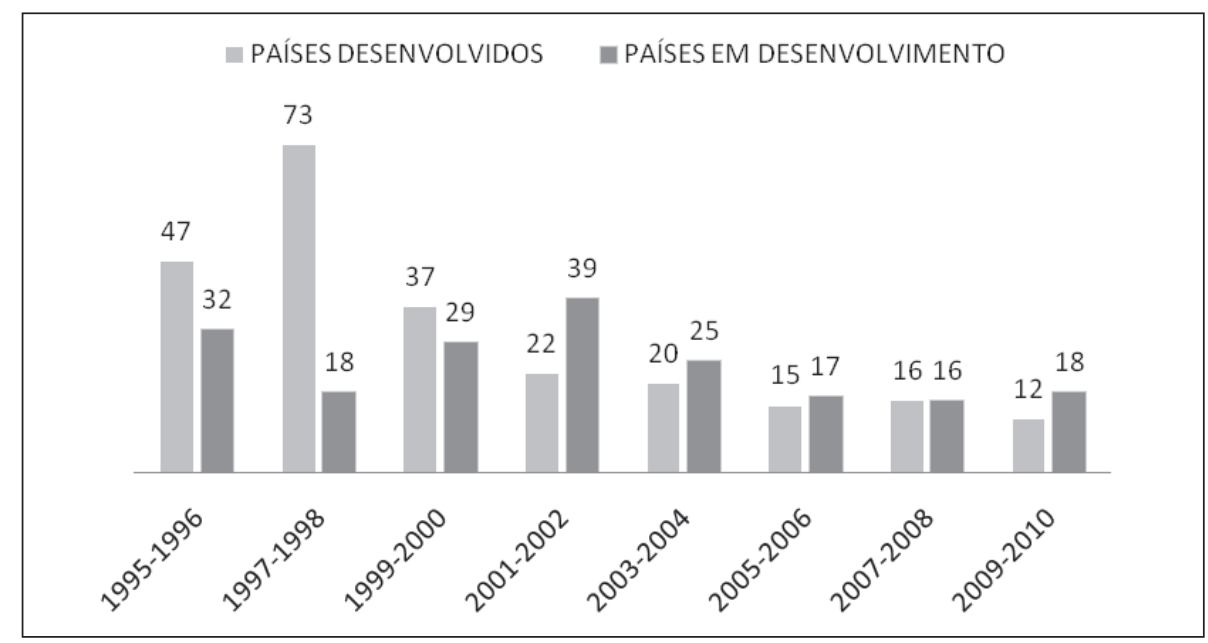

Gráfico 1. Envolvimento de PDs e PEDs em painéis da OMC (1995-2010). ${ }^{13}$ Fonte: WTO (2011).

Cabe notar que o Gráfico 1 não indica uma clara tendência em termos absolutos, isto é, não existe um padrão numérico de painéis por ano em cada uma das categorias ilustradas no gráfico. Os PEDs apresentam um padrão mais consistente de envolvimento em soluções de disputas, tendo variado de 16 a 39 painéis por ano, desde a criação do OSC, em 1995. Por sua vez, os PDs variaram de 12 a 73 painéis por ano. Contudo, nenhum dos casos apresenta uma tendência decrescente ou crescente em termos de painéis por ano. $\mathrm{O}$ que o Gráfico 1 claramente revela é que a lacuna que separa ambas as categorias tem sido reduzida ao longo dos anos. Isso pode decorrer de um processo de aprendizado observado

13 Normalmente os painéis do OSC têm um membro como demandante (complainant) e um membro como demandado (respondent). Entretanto, durante o período considerado houve seis ocasióes nas quais PDs e PEDs se juntaram para questionar políticas comerciais de terceiros. Nesses casos, as partes do painel foram contabilizadas nas suas respectivas categorias. Por exemplo, no DS 217, os Estados Unidos foram acusados de dumping por Austrália, Brasil, Chile, Comunidade Europeia, Índia, Indonésia, Japão, Coreia e Tailândia. Para construir o gráfico, foram registrados 6 PEDs e 3 PDs como demandantes. Assim, o $n$ total apresentado no Gráfico 1 é superior ao número total de painéis registrados no período de 1995 a 2010 pelo fato de um determinado painel poder apresentar mais de um país, PD ou PED, como demandante. 
por alguns PEDs em matéria de solução de disputas e de vocabulário técnico da OMC (Conti 2010).

Associado a essa redução na lacuna está o aumento relativo no número de painéis abertos por PEDs contra PDs (ver Gráfico 2). Novamente, não é possível identificar uma tendência em termos absolutos, mas a comparação entre o desempenho de PDs e PEDs pode ser elucidativa. Mais especificamente, até o biênio 1999-2000 o número de painéis em que os PDs questionaram políticas de um PED é maior do que na situação inversa.

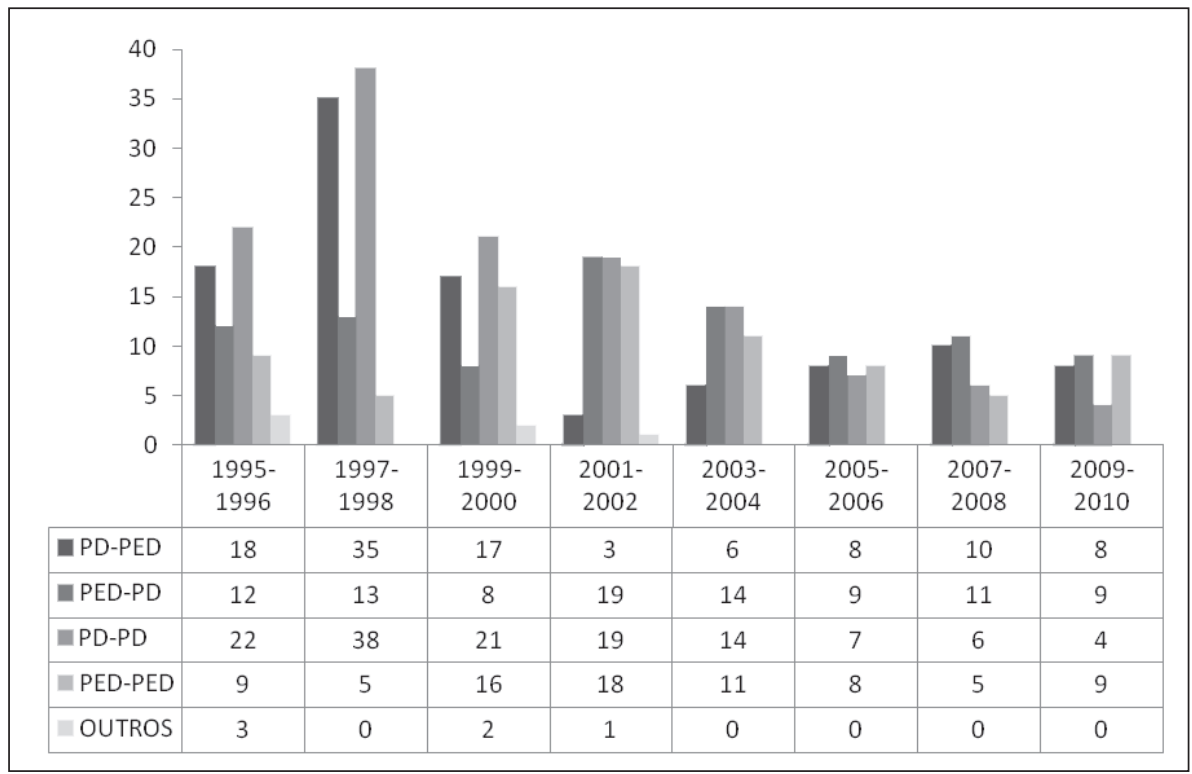

Gráfico 2. Composição de painéis da OMC de acordo com categoria de país membro (1995-2010).

Fonte: WTO (2011).

Lidos conjuntamente, os Gráficos 1 e 2 mostram que, em comparação com os PDs, os PEDs lograram aumentar sua participação nos painéis do OSC da OMC como demandantes, bem como aumentar suas demandas em direção aos PDs por compensação de perdas ou verificação de cumprimento das decisões. A proeminência relativa dos PEDs pode ser explicada por seu processo de aprendizado acerca dos procedimentos do OSC e regras da OMC; além disso, os PEDs também "aprenderam que são capazes de utilizar o mecanismo de disputa para obrigar outros membros a honrar os compromissos assumidos na Rodada Uruguai" (Fernández 2008, 431).

O recurso a mecanismos institucionais a fim de fortalecer as posiçōes relativas é uma estratégia que tem sido utilizado pelos PEDs no âmbito da OMC. Nas negociaçôes sobre apoio doméstico e subsídios à exportação, o contencioso do 
algodão entre os EUA e o Brasil desempenhou um papel importante, uma vez que impulsionou a necessidade de disciplinas mais estritas no apoio doméstico ${ }^{14}$ aos produtores agrícolas (Baffes 2011). O argumento de que os PDs violaram regras da $\mathrm{OMC}$ e prejudicaram os $\mathrm{PEDs}$ com seus subsídios à exportação foi fortalecido após a divulgação, pelo Órgão de Apelação, da decisão favorável ao Brasil na disputa sobre o algodão contra os EUA. Uma demanda ou proposta baseada em elementos institucionais tais como o Mandato de Doha ou a decisão do OSC tende a adquirir força dentro da OMC.

Em termos gerais, o ativismo de alguns PEDs em soluções de disputas pode ser considerado um resultado de investimentos em recursos humanos e financeiros, guiados pela avaliação de que podem obter ganhos por via de regimes multilaterais como a OMC - ou, mais especificamente, o OSC - maiores do que aqueles obtidos diretamente mediante arranjos envolvendo grandes potências (Qureshi 2003). As negociaçõos da OMC oferecem aos PEDs melhores perspectivas do que as negociaçôes Norte-Sul de tipo bilateral. Mesmo que uma negociação multilateral de comércio por si só não neutralize as desigualdades no poder de barganha ou solucione as disparidades em recursos informacionais e organizacionais, a oportunidade de negociar em um sistema institucionalizado aumenta a capacidade de barganha dos PEDs e pode dificultar o unilateralismo das grandes potências.

À luz desse contexto, parece possível considerar a OMC - e o OSC - um regime institucionalizado dinâmico, que passou por mudanças ao longo do tempo ${ }^{15}$. Conforme coloca Krasner (1982), no momento de sua criação, os regimes refletem a distribuição do poder no sistema internacional. Com efeito, a ideia de criar mecanismos de enforcement para o sistema multilateral de comércio foi apresentado pelos EUA, na Rodada Uruguai ${ }^{16}$ e foi inicialmente recebido com hesitação por parte dos PEDs. Particularmente, alguns desses países temiam os "dentes" do mecanismo de solução de controvérsias no que diz respeito à retaliação cruzada. Como muitos PEDs apresentavam direitos de propriedade intelectual mais lenientes, esses países esperavam ser objeto recorrente de retaliação cruzada nesse tema. No entanto, os PEDs acabaram por aceitar a ideia de estabelecer o OSC com dentes por constituir uma via pautada em regras e no multilateralismo, na qual a solução de disputas comerciais se daria de modo institucionalizado.

14 Celso Amorim (2004) argumenta que "recent dispute-settlement cases will fuel the general trend toward more equitable disciplines for world trade in agriculture". Financial Times. "The new dynamic in world trade is multipolar". 4 ago. 2004.

15 Krasner $(1982,499)$ indica que "when regimes are first created there is a high degree of congruity between power distributions and regime characteristics: powerful states establish regimes that enhance their interests. But over time the two can drift apart [...]. By facilitating particular patterns of behavior, regimes can strengthen or weaken the resources of particular actors. Regimes may reinforce or undermine the power capabilities that led to their creation in the first place."

16 Prior to the Uruguay Round, the underlying discussion about how the disputes should be settled also involved the EU. While the US supported a rule-based system, the EU supported a diplomacy-based model (Alavi 2007, 26). 
Regras, normas e procedimentos criados por regimes como o OSC foram cristalizados por meio de rotinas e estruturas burocráticas e começaram a facilitar determinados padrões de comportamento, bem como a afetar os membros como um todo, incluindo aqueles que estimularam a criação desse órgão em sua origem. Nesse sentido, é possível considerar que, do ponto de vista dos PDs, mesmo que uma das ideias iniciais evocadas para promover a criação do OSC estivesse relacionada ao esforço em limitar algumas políticas domésticas dos PEDs e garantir o cumprimento dos acordos assinados nos novos temas de comércio principalmente, propriedade intelectual -, a evolução do sistema permitiu que alguns PEDs desafiassem algumas das políticas domésticas dos PDs contrárias a acordos assinados na OMC e a determinados interesses dos PEDs. Possivelmente, na perspectiva dos PDs, esse é um caso de consequências não esperadas de um órgão internacional. Isso não significa que os PDs não desfrutem de vantagens do sistema; significa que os PEDs também podem recorrer ao OSC para alcançar alguns de seus interesses e fortalecer suas posições relativas. Considerando a ideia de que a estratégia de disputa influencia o uso do direito internacional de comércio, Conti $(2010,658)$ defende que "o efeito da participação repetida [no OSC] não pode ser reduzido à posição econômica no sistema mundial de comércio ou às relaçôes comerciais. Trata-se de uma característica geral de como o sistema é utilizado e de como não é restrito aos mais poderosos".

Apesar da redução proporcional em reclamações junto ao OSC nos últimos anos, os EUA e a UE permanecem como usuários predominantes do sistema legal $\mathrm{da} \mathrm{OMC}$ e, por isso, possuem mais chances de avançar seus principais interesses sistêmicos mediante o processo judicial e a barganha nos bastidores (Shaffer $2005,5)$. Os EUA e a UE participaram como parte ou Terceira parte de aproximadamente $99 \%$ e $86 \%$, respectivamente, dos painéis da OMC que resultaram em uma decisão adotada (Shaffer 2007, 186). Esses números estão diretamente relacionados à capacidade dos EUA e da UE de desenvolver mecanismos para identificar barreiras comerciais no exterior, priorizá-las de acordo com seu impacto e mobilizar recursos para reclamaçóes junto à OMC. Essa coordenação é estruturada em redes envolvendo agências governamentais e o setor privado (op. cit., 179). A maior parte dos PEDs não dispõe desse background de monitoramento das suas relações comerciais.

Os dados apresentados nesta seção indicam que muitos dos PEDs também têm recorrido aos mecanismos institucionais já existentes (tais como o OSC) a fim de fortalecer suas posições relativas na OMC. Como vimos, o recurso desses países ao sistema legal da OMC tem aumentado desde 1995. Essa participação crescente é, entretanto, ainda restrita a um pequeno número de PEDs - notadamente, Brasil (reclamante em 25 painéis), Índia (19), México (21) e Argentina (15). O knowhow adquirido com essa participação constitui uma vantagem significativa em relação àqueles países que não participam do OSC frequentemente (Conti 2010). 


\section{Considerações finais}

A cooperação Sul-Sul é um tema importante dos anos 2000, ainda que seja difícil qualificar a sua singularidade em termos históricos. O fenômeno tem adquirido diferentes formas e contribuído na busca por mudanças nas estruturas de governança internacional. Na OMC, particularmente na Rodada Doha, a cooperação entre $\mathrm{PEDs}$ pode ser verificada pelo aumento quantitativo e qualitativo das coalizões envolvendo países do Sul. Em situações onde as capacidades econômicas, políticas e técnicas dos países não possibilitam participação efetiva nas negociações, a formação de coalizôes apresentou-se como uma alternativa possível, que fortalece o poder de barganha.

A formação de coalizões e a utilização de mecanismos institucionais para fortalecer posições relativas são duas estratégias importantes utilizadas pelos países em desenvolvimento para aumentar o seu peso no sistema multilateral de comércio, potencializadas por um contexto internacional em transformação. Ao mesmo tempo, observou-se que os países do Sul não são um grupo homogêneo e têm dificuldade de agir conjuntamente, principalmente, nos estágios finais da negociação, como evidenciado pela dificuldade de coordenação de políticas na reunião ministerial de Genebra, de julho de 2008. Ou seja, a visão dos países em desenvolvimento sobre a forma de lidar com negociações e temas globais não é sempre convergente.

$\mathrm{O}$ maior ativismo interno dos $\mathrm{PEDs}$ na estrutura da $\mathrm{OMC}$ tem relação com as possibilidades visualizadas pela utilização do Órgão de Solução de Controvérsias. Como foi demonstrado, no período pós-2001, é possível identificar maior participação dos PEDs como demandantes em painéis no OSC, o que sinaliza que esses países têm uma expectativa de ganhos, apesar dos custos da ação. $\mathrm{O}$ adensamento da participação no OSC indica certa tentativa de utilizar mecanismos institucionais para viabilizar ganhos mediante canais multilaterais, visando a aferir benefícios da negociação num ambiente institucionalizado.

Mesmo assim, é importante ressalvar, como os dados apresentados demonstram, que a participação efetiva dos países em desenvolvimento no OSC ainda é concentrada num grupo relativamente pequeno de países. Brasil e Índia, que tiveram um papel central na coalizão G-20, são também os principais ativadores do OSC entre os países em desenvolvimento. Esses países têm buscado modificar a estrutura do sistema de comércio visando a torná-la mais permeável aos seus interesses. A evolução das negociações no período de 2001 a 2008 indica ser improvável que a Rodada Doha seja concluída com os PDs impondo uma distribuição totalmente assimétrica de ganhos aos PEDs, como ocorria nas Rodadas anteriores (Steinberg 2002).

As mudanças verificadas na dinâmica das negociações da $\mathrm{OMC}$ são guiadas por mudanças estruturais na distribuição de poder internacional conjugadas com aspectos internos à organização e às estratégias dos PEDs, fruto do aprendizado e 
adaptação comportamental com as regras e normas da organização. Uma implicação importante da estratégia de formação de coalizões e maior participação dos PEDs no OSC é que o regime de comércio internacional terá que refletir de forma mais efetiva os seus interesses. Essa seria uma mudança significativa, cuja consolidação não é simples. A atuação dos PEDs na Rodada Doha é informada por uma crítica à estrutura internacional protagonizada pelos $\mathrm{PDs}$ e por um ativismo interno que busca redefinir o seu papel e a própria configuração da OMC.

\section{Referências bibliográficas}

ALDEN, Chris; VIEIRA, Marco Antonio. (2005). "The New Diplomacy of the South: South Africa, Brazil, India and Trilateralism”. Third World Quarterly, 26 (7), 1077-1095.

ALAVI, Amin (2007). "African countries and the WTO's Dispute Settlement Mechanism". Development Policy Review, 25 (1), 25-42.

AMORIM, Celso L. N. "Seven years of progress, expansion”. The Miami Herald, 13 Sept. 2010.

BAFFES, John. Cotton Subsidies, the WTO, and the "Cotton problem". The World Economy, vol. 34, 9, pp. 1534-556, 2011.

BUZAN, Barry. (2004). The United States and the great powers. World politcs in the twenty-first century. Cambridge: Polity Press.

CLARÍN (2008). "Lula, en exclusiva con Clarín: 'no existe ninguna hipótesis de que Brasil se juegue solo.” Disponível em <http://edant.clarin.com/diario/2008/09/07/um/m-01755400. htm>, acessado em 11 out. 2011

CONTI, Joseph A. (2010). "Learning to Dispute: repeat participation, expertise, and reputation at the World Trade Organization”. Law \& Social Inquiry, 25, (3), 625-662.

CONSTANTINI, Valeria; CRESCENZI, Riccardo(2007). "Bargaining Coalitions in the WTO Agricultural Negotiations". The World Economy, 30 (5), 863-891.

DEESE, David A. (2008). World Trade Politics. Power, Principles, and leadership. New York: Routledge.

DRAHOS, Peter. (2003). "When the Weak Bargain with the Strong: Negotiations in the WTO”. International Negotiation, 8 (1), 79-103.

FARIAS, Rogério S. (2009). O Brasil e o GATT (1973-1993): unidades decisórias e política externa. Curitiba: Juruá, 2009.

FERNÁNDEZ, Diego M. (2008). "Trade negotiations make strange bedfellows." World Trade Review, 7(2): 423-453.

HARDIM, Russell. (1982). Collective Action. Baltimore: The John Hopkins University Press.

HURRELL, Andrew; NARLIKAR, Amrita. "A New politics of confrontation? Developing countries at Cancun and beyond." Global Society, 20(4): 415-433.

IKENBERRY, John G. (2008). "The Rise of China and the Future of the West." Foreign Affairs, 87: 23-37. 
ISMAIL, Faizel. (2007). The G-20 and NAMA-11: The role of Developing Countries in the WTO and Doha Round. Paper presented at the GEG Seminar Series on Making Globalization Work for Developing Countries. Oxford.

ISMAIL, Faizel. (2009). "An assessment of the WTO Doha Round July - December 2008 collapse." World Trade Review, 8(4): 579-605.

KEOHANE, Robert O. (1984). After Hegemony: Cooperation and Discord in the World Political Economy. Princeton: Princeton University Press.

KRASNER, Stephen. D. (1982). "Structural causes and regime consequences: regimes as intervening variables." International Organization, 36(4): 497-510.

KUPCHAN, Charles A. (2002). "Hollow hegemony or stable multipolarity?". In American Unrivaled: the future of the balance of power edited by Ikenberry, G. J. 68-98. Ithaca/London: Cornell University Press.

MINISTÉRIO das RELAÇÕES EXTERIORES. (2007). “O G-20 e a OMC.” Textos, Comunicados e Documentos. Brasília: Fundação Alexandre de Gusmão.

MOSOTI, Victor. Does Africa need the WTO dispute settlement system? In: ICTSD Resource paper No. 5, March 2003, pp. 67-88. Disponível em <http://ictsd.org/downloads/2008/06/ dsu_2003.pdf>, acessado em 24 jul. 2012.

NARLIKAR, Amrita. (2003). International Trade and Developing Countries: bargaining coalitions in the GATT \& WTO. London: Routledge.

NARLIKAR, Amrita; TUSSIE, Diana (2004). “The G-20 at the Cancun Ministerial: Developing Countries and their evolving coalitions in the WTO." World Economy, 27(7): 947-1148.

ODELL, John S. (2003). Developing Countries and the Trade Negotiation Process. Paper presented at the Conference on Developing Countries and the Trade Negotiation Process, UNCTAD, Palais des Nations, Geneva.

OLSON, Mancur. (1999). A Lógica da Ação Coletiva. São Paulo: EDUSP.

OSTRY, Sylvia. (2002). “The Uruguay Round North-South Grand Bargain: implications for future negotiations". In The political economy of international trade law (Kennedy, D. L.M. and J.D. Southwick (eds.)). Cambridge: Cambridge University Press, pp. 285-300.

PAALBERG, Robert. (1997). "Agricultural Policy reform and the Uruguay Round: Synergistic linkage in a two-level game." International Organization, 51(3): 413-444.

PATEL, Mayur (2007). New faces in the Green Room: Developing Country Coalitions and Decision - Making in the WTO. Paper presented at the Global Trade Governance Project. Oxford.

QURESHI, Asif. H. (2003). "Participation of Developing Countries in the WTO Dispute Settlement System.” Journal Of African Law, 47(2): 174-198.

RAMANZINI JÚNIOR, Haroldo. (2009). Processo decisório de politica externa e coalizóes internacionais: as posições do Brasil na OMC. Dissertação de Mestrado. Departamento de Ciência Política, Universidade de São Paulo.

SHAFFER, Gregory. (2006). “The challenges of WTO law: strategies for developing country adaptation.” World Trade Review, 5(2): 177-198. 
SHAFFER, Gregory. (2005). Developing country use of WTO dispute settlement system: why it matters, the barriers posed, and its impact on bargaining. Paper presented at "WTO at 10: a look at the Appellate Body," São Paulo, Brazil.

SRIVASTAVA, Sanjay. (2008). "Negotiation Analysis: the Cancun Ministerial of the WTO." International Studies, 45(1): 23-43.

STEINBERG, Richard. (2002). "In the shadow of law or power? Consensus - based bargaining and outcomes in the GATT/WTO.” International Organization, 56(2): 339-374.

TUSSIE, Diana; GLOVER, David. (1995). The developing countries in world trade: policies and bargaining strategies. Boulder CO: Lynne Rienner.

TUSSIE, Diana. (2009). Process Drivers in Trade Negotiations: the role of research in the path to grounding and contextualizing. Latin American Trade Network (LATN)/Série BRIEF.

VELASCO e CRUZ, Sebastião C. (2007). Trajetórias: capitalismo neoliberal e reformas econômicas nos países da periferia. São Paulo: Editora da Unesp.

VIGEVANI, Tullo; RAMANZINI JÚNIOR, Haroldo (2010). "The changing nature of multilateralism and Brazilian foreign policy.” In International Spectator, 45(4): 63-71.

WILKINSON, Rorden. (2006). The WTO: Crisis and the governance of global trade. New York: Routledge.

WORLD TRADE ORGANIZATION (2011). Chronological List of Disputes Cases. Disponível em <http://www.wto.org/english/tratop_e/dispu_e/dispu_status_e.htm>, acessado em 8 nov. 2011.

Recebido em 25 de março de 2012

Aprovado em 31 de julho de 2012

\section{Resumo}

Este artigo analisa a atuação dos países em desenvolvimento (PEDs) no âmbito da Organização Mundial do Comércio (OMC), bem como o impacto dessa atuação na dinâmica da organização. A análise é articulada a partir de dois aspectos: as coalizões envolvendo PEDs e a participação desses países no Órgão de Solução de Controvérsias (OSC). Os autores concluem que o recurso a mecanismos institucionais constitui a principal estratégia dos PEDs para aumentar sua capacidade relativamente aos países desenvolvidos (PDs). Nesse sentido, os PEDs têm atuado dentro da estrutura de comércio existente, buscando adaptá-la a seus interesses. Esses países lograram criar e manter coalizões na OMC, apesar de sua diversidade econômica e política. Quanto à sua participação no OSC, ainda que o número de painéis abertos por PEDs tenha aumentado, essas disputas ainda concentram-se em um número pequeno de PEDs - principalmente Brasil e Índia.

Palavras-chave: coalizões; Organização Mundial do Comércio; Órgão de Solução de Controvérsias; países desenvolvidos; países em desenvolvimento. 


\begin{abstract}
This article analyzes developing countries performance at the World Trade Organization (WTO) accordingly to two aspects: developing country coalitions and developing country participation in the Dispute Settlement Body (DSB). The authors conclude that developing countries use institutional mechanisms as their main strategy in order to increase their capacity relatively to developed countries. Thus, developing countries have worked within the existing trade structure in order to try to adapt it to their interests. Developing countries have managed to create and maintain coalitions at the WTO, despite their economic and political diversity. As regards their participation in the DSB, although the number of panels opened by developing countries has increased, it is still concentrated in a small group of developing countries, mainly Brazil and India.
\end{abstract}

Keywords: coalitions; World Trade Organization; Dispute Settlement Body; developed countries; developing countries. 